\title{
NUMERICAL SIMULATION OF FLUID FLOW INSIDE THE FLOW CONTROL VALVE
}

doi: 10.2478/cqpi-2019-0053

Date of submission of the article to the Editor: 01/04/2019

Date of acceptance of the article by the Editor: 27/05/2019

\author{
Mariusz Domagała ${ }^{1}$ - orcid id: 0000-0001-9642-6142 \\ Hassan Momeni ${ }^{2}$ \\ Joanna Fabis-Domagała ${ }^{1}$ - orcid id: 0000-0003-2811-1100 \\ Mariusz Krawczyk ${ }^{1}$ \\ Grzegorz Filo ${ }^{1}$ - orcid id: 0000-0003-0848-6124 \\ Saeed Bikass ${ }^{2}$ \\ ${ }^{1}$ Cracow University of Technology, Institute of Applied Informatics, Jana Pawla II 37, 31-841 \\ Cracow, Poland \\ ${ }^{2}$ Western Norway University of Applied Sciences, Department of Mechanical and Marine \\ Engineering, Inndalsveien 28, 5063 Bergen, Norway
}

Abstract. Hydraulic valves are widely used in many branches and they are still developed and improved. Due to the problem with verification of flow phenomena which appears during valves operation numerical simulations methods are tools which allows to improved valves design. This paper presents numerical simulation of fluid flow inside flow control valve.

Keywords: hydraulic system protection, safety valve, relief valve, numerical modelling, test bench experiments

\section{INTRODUCTION}

Fluid power components, particularly valves, are widely used in many industrial branches, from manufacturing to heavy machinery. Valves are used in a power and control systems. The latest tendency in fluid power technology is implementing electronic systems in hydraulic valves what allows to obtain new possibilities, mostly in control functions. Improvement of valves quality in aspect of control might be achieved by detailed modelling mechanical parts. However, it is a complex task due to the relatively small dimensions and complex phenomena which appears during fluid flow. One of the tool which might be used in modelling vales operation particularly is simulation of flow of working fluid is CFD (Computational Fluid Dynamics). This numerical methods use RANS (Reynolds Averaged Navier-Stokes) equations which defines scalars (e.g. velocity) as a mean values and fluctuations over this value. Such approach is very practical because in engineering practice information about each vortex, even the smallest one sometimes is not required. RANS defines fluid velocity as:

$$
\mathrm{u}_{\mathrm{i}}=\overline{\mathrm{u}}_{\mathrm{i}}+\mathrm{u}_{\mathrm{i}}^{\prime}
$$


where $\bar{u}_{i}$ - is the mean velocity value, $u_{i}^{\prime}$ - is the fluctuating velocity, i stands for velocity component.

RANS equations have the following form:

$$
\begin{aligned}
& \frac{\partial \rho}{\partial \mathrm{t}}+\frac{\partial \rho}{\partial \mathrm{x}_{\mathrm{i}}}\left(\rho \mathrm{u}_{\mathrm{i}}\right)=0 \\
& \frac{\partial \rho}{\partial \mathrm{t}}\left(\rho \mathrm{u}_{\mathrm{i}}\right)+\frac{\partial \rho}{\partial \mathrm{x}_{\mathrm{j}}}\left(\rho \mathrm{u}_{\mathrm{i}} \mathrm{u}_{\mathrm{j}}\right)=-\frac{\partial \mathrm{p}}{\partial \mathrm{x}_{\mathrm{i}}}+\frac{\partial}{\partial \mathrm{x}_{\mathrm{j}}}\left[\mu\left(\frac{\partial \mathrm{u}_{\mathrm{i}}}{\partial \mathrm{x}_{\mathrm{j}}}+\frac{\partial \mathrm{u}_{\mathrm{j}}}{\partial \mathrm{x}_{\mathrm{i}}}-\frac{2}{3} \delta_{\mathrm{ij}} \frac{\partial \mathrm{u}_{\mathrm{i}}}{\partial \mathrm{x}_{\mathrm{i}}}\right)\right]+\frac{\partial}{\partial \mathrm{x}_{\mathrm{j}}}\left(-\rho \overline{\mathrm{u}_{\mathrm{i}} \mathrm{u}_{\mathrm{j}}}\right)
\end{aligned}
$$

where: $\rho$ - is the fluid density, $u$ - is the fluid velocity, $p$ - is pressure, $\mu$ - is the fluid dynamic viscosity, $\delta$ - is the Kronecker function.

Additional term which appears in Eq. (3) $-\rho \overline{\mathrm{u}_{1} \mathrm{u}_{j}}$ represents the effects of turbulence (called Reynolds stress) and makes that the set of Eq. (2) and Eq. (3) is not closed, therefore this term has to be modeled. There are few methods for closure RANS equations which are called turbulence models:

- zero equation turbulence models,

- one equation turbulence models,

- two equations turbulence models,

Above models use the Boussinesq hypothesis:

$$
-\rho \overline{\mathrm{u}_{1} \mathrm{u}_{\mathrm{j}}}=\mu_{\mathrm{t}}\left(\frac{\partial \mathrm{u}_{\mathrm{i}}}{\partial \mathrm{x}_{\mathrm{j}}}+\frac{\partial \mathrm{u}_{\mathrm{j}}}{\partial \mathrm{x}_{\mathrm{i}}}\right)-\frac{2}{3} \delta_{\mathrm{ij}}\left(\rho \mathrm{k}+\mu_{\mathrm{t}} \frac{\partial \mathrm{u}_{\mathrm{k}}}{\partial \mathrm{x}_{\mathrm{k}}}\right)
$$

There are also turbulence models which does not use the Boussinesq hypothesis like Reynolds stress models.

CFD tools allows to simulate fluid flow inside valves as well as simulations of phenomena which may cause valves failure or malfunction (Domagala et al., 2018a; Domagala et al., 2018b).

\section{FLOW CONTROL VALVE}

Flow control valve function is to maintain constant flow rate independently on pressure to inlet or outlet. Valve presented in Fig. 1. is a flow control valve controlled by proportional solenoid. The valve itself consists of two valve: throttle valve and compensation valve which means that the valve can be characterized as a structure with high scale of complexity. The value of flow rate which will be maintain in the system is set by the position of the spool on the left side. Constant flow rate is maintain by the position of the spool on the right side, which is determined by the flow conditions on inlet and outlet.

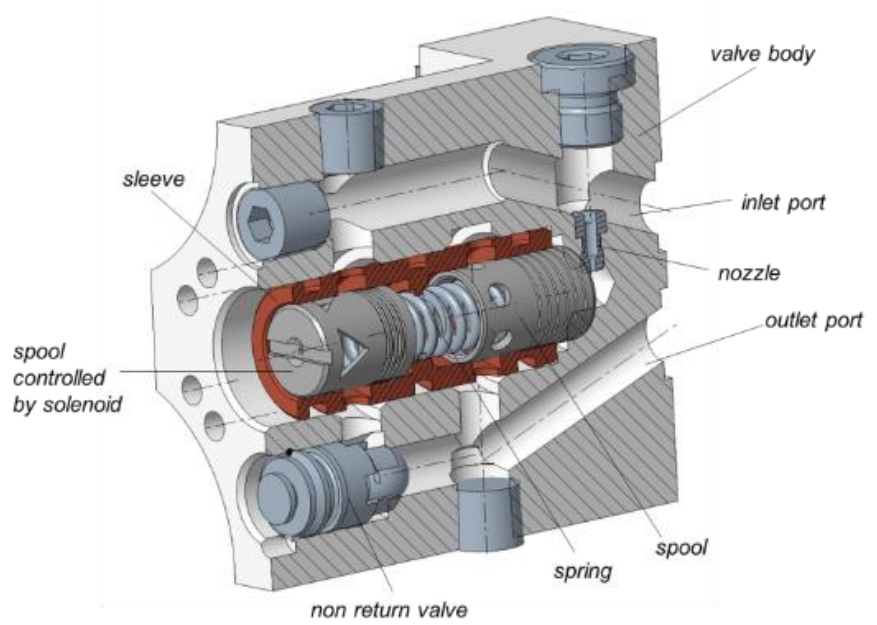

Fig. 1. Flow control valve. 


\section{NUMERICAL SIMULATION OF FLOW INSIDE FLOW CONTROL VALVE}

Numerical simulations of fluid flow inside hydraulic valves are conducted for various goals, to investigate flow forces (Domagala, 2008; Lisowski et al., 2015; Lisowski et al., 2016; Lisowski et al., 2018) or to investigate dynamic behavior of valve components (Beune et al., 2012; Domagala, 2016).

Fluid flow inside the flow control valve is determined by position of spools, the left side spool position is set by solenoid while position of the second depends on flow conditions on inlet and outlet. Therefore, the flow simulation was conducted for two models as it is presented in Fig. 2. Results of numerical simulation of the part which includes spool set by solenoid are used as input data for the second model.

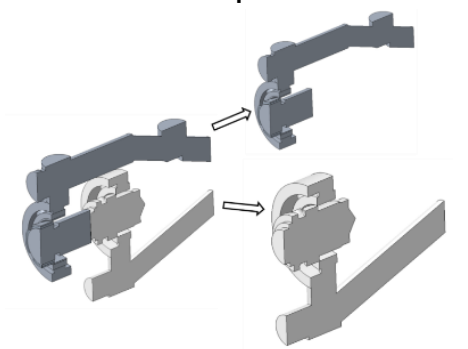

Fig. 2. Flow domains of flow control valve.

CFD simulation was performed in ANSYS CFX code for fixed component position for steady state conditions and for the following assumptions: (a) fluid (hydraulic oil) is homogeneous and has a constant properties: density $880[\mathrm{~kg} / \mathrm{m} 3]$, viscosity $v=40$ $\left[\mathrm{mm}^{2} / \mathrm{s}\right]$; (b) flow is turbulent: k- $\mathrm{w}$ turbulence model was used; (c) model is in thermodynamics equilibrium, heat transfer is not included; (d) half of the geometrical model was used in simulations. An exemplary results of fluid flow inside flow control valve are shown in Fig.3 and Fig.4.
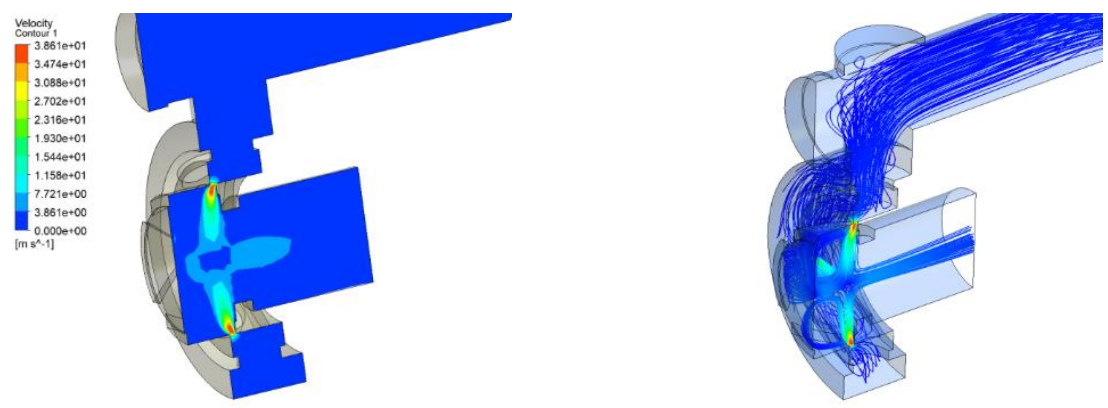

Fig. 3. Velocity distribution (left side, in $\mathrm{m} / \mathrm{s}$ ) and pathlines (right side) for the part with spool controlled by solenoid
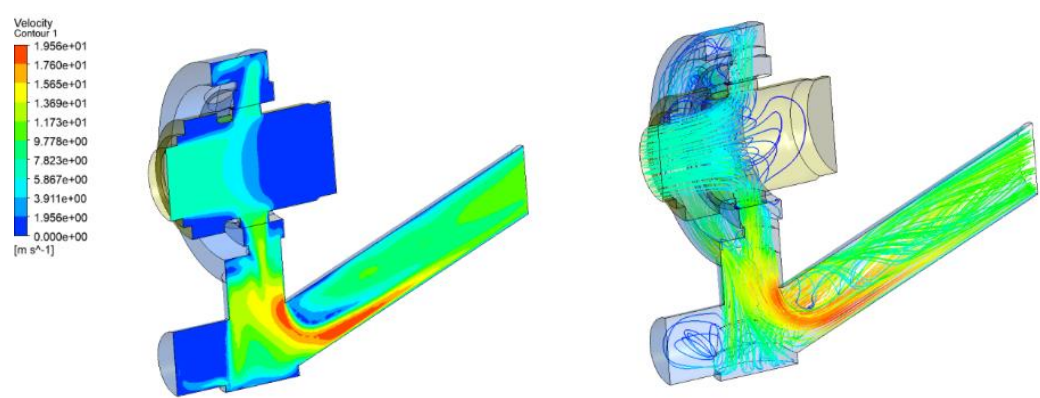

Fig. 4. Velocity distribution (left side, in $\mathrm{m} / \mathrm{s}$ ) and pathlines (right side) for the part with second spool. 
Numerical simulations of flow inside the valve allowed also to obtain pressure drop at the first spool (controlled by solenoid) which is presented in Fig.5. Spool position is normalized value, where 0 is initial position (valve is closed) while 1 is fully open valve.

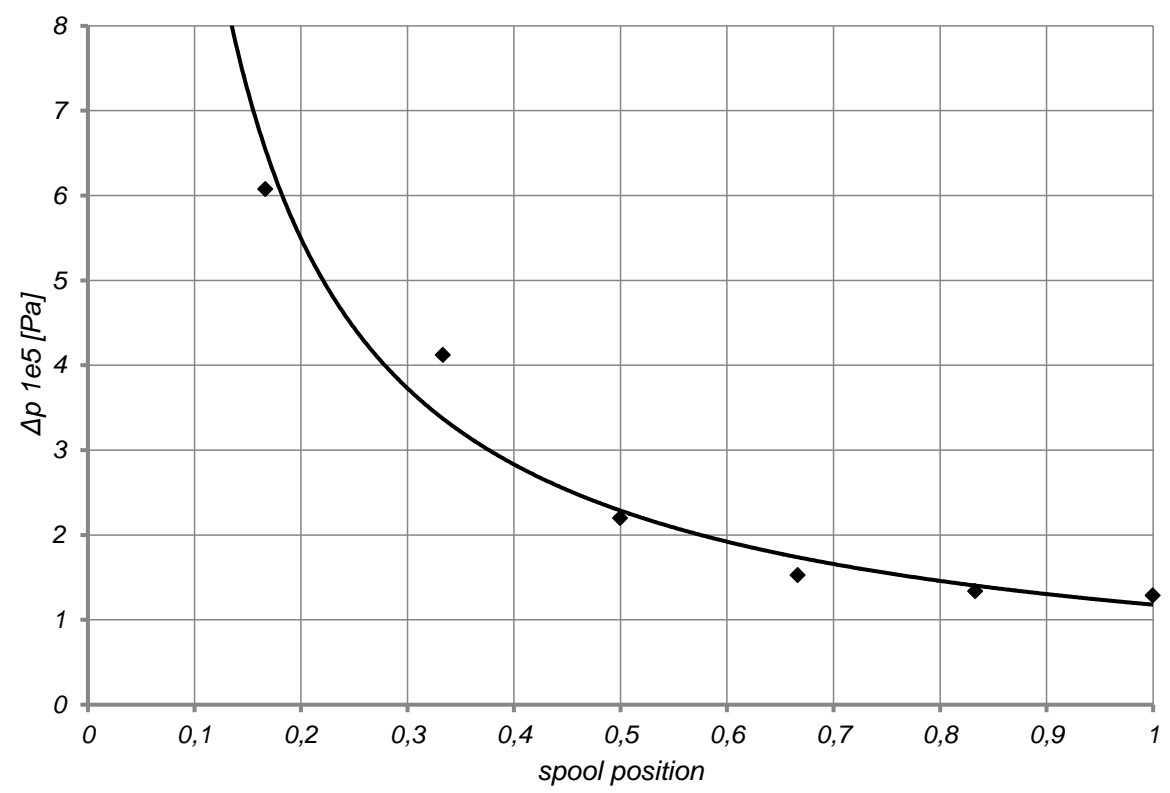

Fig. 5. Pressure drop during flow at the spool controlled by solenoid.

\section{CONCLUSIONS}

Numerical simulations of flow inside valves bring new quality in modelling such components. Information which are obtained during CFD simulation allows to investigate phenomena which appears during fluid flow which might be used during design process. Due to the problems with experimental tests of fluid flow inside valves numerical tools seems to be very efficient design tool which might be used as a virtual test stand for verification of assumptions and requirements. Results of CFD simulations might be also used for adjusting electronic control systems.

Obtained results may be used in construction of heavy-duty machines hydraulic systems (Pobedza and Sobczyk, 2013; Krawczyk and Sobczyk, 2018) or in a precision control of a flow in biotechnology reactors (Skrzypczak-Pietraszek et al., 2018). A methodology presented may be also useful in materials science, in modeling of structure modifications (Lipinski and Wach, 2014) or surface modifications (GadekMoszczak et al., 2014; Bara et al.,2016; Opydo et al., 2016; Radek et al., 2018). It may be also used in an uncertainty quantification (Pietraszek et al., 2016; Kozien and Kozien, 2017) and related risk management (Kielbus and Karpisz, 2019) as a tool for construction of a surrogate model (Ferdek and Kozien, 2013). Finally, the results should be widely disseminated in academia and industry by scientific and industrial databases (Gawlik et al., 2015; Karpisz and Kielbus, 2018).

\section{REFERENCES}

Bara, M., Kmita, T., Korzekwa, J., 2016. Microstructure and properties of composite coatings obtained on aluminium alloys. Arch. Metall. Mater., 61, 1107-1112. DOI: 10.1515/amm-2016-0238 
Beune A., Kuerten J.G.M., van Heumen M.P.C., 2012. CFD analysis with fluid-structure interaction of opening high-pressure safety valves, Computers \& Fluids, 64, 108116. DOI: 10.1016/j.compfluid.2012.05.010

Domagala M., 2008. CFD analysis of pilot operated relief valve, Technical Transactions. Mechanics, 3-M, 23-29

Domagala M., 2015. Modelling of direct acting relief valve using CFD-FSI simulation, Technical Transactions. Mechanics, 2-M, 43-48

Domagala, M., Momeni, H., Domagala-Fabis, J., Filo, G., Krawczyk, M., $2018 a$. Simulation of Cavitation Erosion in a Hydraulic Valve. Materials Research Proceedings, 5, 1-6. DOI: 10.21741/9781945291814-1

Domagala, M., Momeni, H., Domagala-Fabis, J., Filo, G., Kwiatkowski, D., 2018b. Simulation of Particle Erosion in a Hydraulic Valve. Materials Research Proceedings, 5, 17-24. DOI: 10.21741/9781945291814-4

Ferdek, U.; Kozien, M. S. 2013. Simulation of Application of FGM Piezoelectric Actuators for Active Reduction of Beam Vibrations. Acta Physica Polonica A, 123, 1044-1047. DOI: 10.12693/APhysPolA.123.1044

Gadek-Moszczak, A., Radek, N., Wronski, S., Tarasiuk, J., 2014. Application the 3D image analysis techniques for assessment the quality of material surface layer before and after laser treatment. Adv. Mat. Res. Switz., 874, 133-138. DOI: 10.4028/www.scientific.net/AMR.874.133

Gawlik, J., Kielbus, A., Karpisz, D., 2015. Application of an integrated database system for processing difficult material. Solid State Phenomena, 223, 35-45. DOI: 10.4028/www.scientific.net/SSP.223.35

Karpisz, D., Kielbus, A., 2018. Selected problems of designing modern industrial databases. MATEC Web Conf., 183, art. 01017. DOI: 10.1051/matecconf/201818301017

Kielbus, A., Karpisz, D., 2019. Risk management as a process security tool. System Safety: Human-Technical Facility-Environment, 1, 234-239. DOI: 10.2478/czoto2019-0030

Kozien, E., Kozien, M.S., 2017. Interval analysis as a method of measurement of uncertainity in the check-list method applied to identification of stage phase of companies. $26^{\text {th }}$ Int. Scientific Conf. Economic and Social Development. Zagreb, Varazdin, 210-215.

Krawczyk, J., Sobczyk, A., 2018. Tests of New Methods of Manufacturing Elements for Water Hydraulics. Materials Research Proceedings, 5, 200-205. DOI: 10.21741/9781945291814-35

Lipinski, T., Wach, A., 2014. Influence of outside furnace treatment on purity medium carbon steel. Metal 2014: $23^{\text {rd }}$ Int. Conf. Metallurgy And Materials, Ostrava, Tanger, 738-743.

Lisowski E., Filo G., Rajda J., 2015. Pressure compensation using flow forces in a multisection proportional directional control valve, Energy Conv. Manag., 103, $1052-$ 1064. DOI: 10.1016/j.enconman.2015.07.038

Lisowski E., Filo G., Rajda J., 2018. Analysis of flow forces in the initial phase of throttle gap opening in a proportional control valve, Flow Meas. Instrum., 59, 157-167. DOI: 10.1016/j.flowmeasinst.2017.12.011

Lisowski E., Filo G., Rajda J., 2016. CFD analysis of the characteristics of a proportional flow control valve with an innovative opening shape, Energy Conv. Manag., 123, 1528. DOI: 10.1016/j.enconman.2016.06.025 
Opydo, M., Kobylecki, R., Dudek, A., Bis, Z. 2016. The effect of biomass co-combustion in a CFB boiler on solids accumulation on surfaces of P91 steel tube samples. Biomass \& Bioenergy, 85, 61-68. DOI: 10.1016/j.biombioe.2015.12.011

Pietraszek, J., Kolomycki, M., Szczotok, A., Dwornicka, R., 2016. The fuzzy approach to assessment of ANOVA results. ICCCI 2016: Conf. on Comp. Collective Intell. Springer, 260-268. DOI: 10.1007/978-3-319-45243-2_24

Pobedza, J., Sobczyk, A., 2013. Modern Coating Used in High Pressure Water Hydraulic Components. Key Engineering Materials, 542, 143-155. DOI: 10.4028/www.scientific.net/KEM.542.143

Radek, N., Szczotok, A., Gadek-Moszczak, A., Dwornicka, R., Broncek, J., Pietraszek, J., 2018. The impact of laser processing parameters on the properties of electrospark deposited coatings. Arch. Metall. Mater., 63, 809-816. DOI: 10.24425/122407

Skrzypczak-Pietraszek, E., Reiss, K., Zmudzki, P., Pietraszek, J., 2018. Enhanced accumulation of harpagide and 8-O-acetyl-harpagide in Melittis melissophyllum $L$. agitated shoot cultures analyzed by UPLC-MS/MS. PLoS ONE 2018, 13, art. e0202556. DOI: 10.1371/journal.pone.0202556

Szczotok, A., Radek, N., Dwornicka, R., 2018. Effect of the induction hardening on microstructures of the selected steels. METAL 2018: $27^{\text {th }}$ Int. Conf. Metallurgy and Materials. Ostrava, Tanger, 1264-1269. 